\title{
Effects of Ibuprofen on the physiology and outcome of rabbit endotoxic shock \author{
Mukaddes Canbaz ${ }^{3}$ and Suleyman Felek ${ }^{1}$
} \\ Ilhami Celik*1, Ayhan Akbulut1, S Sirri Kilic ${ }^{1}$, Ali Rahman², Pervin Vural ${ }^{3}$,
}

Address: ${ }^{1}$ Department of Clinical Microbiology and Infectious Diseases, College of Medicine, Firat University, Elazig, Turkey, ${ }^{2}$ Department of Cardiovascular Surgery, College of Medicine, Firat University, Elazig, Turkey and ${ }^{3}$ Department of Clinical Biochemistry, College of Medicine, Istanbul University, Istanbul, Turkey

E-mail: Ilhami Celik* - ilhamicelik@hotmail.com; Ayhan Akbulut - a_akbulut@yahoo.com; S Sirri Kilic - sskilic@yahoo.com; Ali Rahman - arahman33@hotmail.com; Pervin Vural - pervinvural@dostmail.com; Mukaddes Canbaz - mcanbaz@istanbul.edu; Suleyman Felek - feleks@hotmail.com

${ }^{*}$ Corresponding author

Published: 31 October 2002

Received: 20 April 2002

BMC Infectious Diseases 2002, 2:26

Accepted: 31 October 2002

This article is available from: http://www.biomedcentral.com/I47I-2334/2/26

(C) 2002 Celik et al; licensee BioMed Central Ltd. This article is published in Open Access: verbatim copying and redistribution of this article are permitted in all media for any purpose, provided this notice is preserved along with the article's original URL.

\begin{abstract}
Background: Despite major developments in the management of septic shock, the mortality rate had progressively increased. Ibuprofen has been shown to have beneficial physiological effects when used as a treatment. However, there are conflicting results with respect to survival. This study aims to investigate the effect of ibuprofen on vital functions, various physiological parameters and survival during endotoxic shock in rabbits.
\end{abstract}

Methods: Twenty-eight New Zealand rabbits were randomly separated into four groups. The first group received only saline, the second was given $2 \mathrm{mg} / \mathrm{kg}$ intravenous endotoxin at $\mathrm{t}_{0}$, the third received $30 \mathrm{mg} / \mathrm{kg}$ ibuprofen 30 minutes after endotoxin administration, whilst the fourth group received ibuprofen 30 minutes before the endotoxin. Respiratory and heart rate, mean arterial blood pressure and rectal temperature were recorded. Complete blood counts were performed and thromboxane $B_{2}$ was measured every 30 minutes for the first two hours, and then hourly over the course of the experiment. Urine samples were collected at the same time points for the measurement of prostaglandin $E_{2}$.

Results: Ibuprofen was found to improve respiratory rate, heart rate, and arterial pressure. However, it did not improve the negative effects of endotoxin on body temperature, haematocrit values, white blood cell count, and thrombocyte number. Thromboxane $B_{2}$ levels in group IV were significantly lower than in the other groups, and the increase started at a later timepoint. In ibuprofen-treated animals, Prostaglandin $\mathrm{E}_{2}$ levels stayed low for at least 90 minutes, but started to rise thereafter. While the average survival in Group II animals was $192.9 \pm 46.9$ minutes, those of groups III and IV were 339.I \pm 33.5 minutes $(p<0.05)$ and $383.0 \pm 39.6$ minutes $(p=0.01)$, respectively.

Conclusions: Ibuprofen appears to increase survival in endotoxic shock-induced animals. Therefore, it may be helpful for the prophylaxis and treatment of patients with, or who are likely to develop, septic shock. 


\section{Background}

Although there have been major developments in its diagnosis and treatment, the mortality rate of septic shock has progressively increased over the past few decades. The mortality rate can be as high as $60-70 \%$ in cases with multi-organ failure [1], and several pharmacological agents have been used in an effort to reduce this percentage [2].

In endotoxic shock, bacterial endotoxin enters the systemic circulation and triggers the release of pro-inflammatory mediators. Prostaglandin is released during inflammatory reactions, causing an increase in microvascular hydrostatic pressure, which is a primary cause of edema and a contributory factor in hypovolemia $[3,4]$.

Non-steroidal anti-inflammatory agents (NSAIDs), such as acetyl salicylic acid and indometasin, have been used in the treatment of sepsis and septic shock, and an improvement in survival has been noted. Several researchers have also evaluated ibuprofen, and beneficial effects on pathophysiological changes have been observed [3]. The first major study of ibuprofen in endotoxic shock was performed by Jacobs et al.[5]. This study indicated that ibuprofen can limit the degree of hypotension and acidosis, and decrease the cardiac index in endotoxic shock. Fink et al. [6] reported that ibuprofen restored the normal hemodynamic pattern. However, Hulton et al. [7] saw no major metabolic effect in E. coli sepsis. Coran et al.[8] showed that the administration of ibuprofen in septic shock in dogs did not reduce cytokine levels. Herbertson et al.[9] showed that ibuprofen administration in endotoxic shock in pigs could prevent the early hemodynamic changes following entotoxemia, but not the later changes. Bernard et al. [10] reported that, in patients with sepsis, treatment with ibuprofen reduced levels of prostacylin and thromboxane and decreased fever, tachycardia, oxygen consumption, and lactic acidosis, but did not prevent the development of shock or acute respiratory distress syndrome, and did not improve survival.

Despite several studies using ibuprofen in endotoxic and septic shock models, there are some conflicting results with respect to survival, and there are few studies using pre-treatment with ibuprofen. In this study, we investigated the effects of ibuprofen on physiological parameters and survival in pre- and post-treated rabbits with experimentally induced endotoxic shock.

\section{Methods}

\section{Preparation of animals}

Twenty-eight New Zealand rabbits were anaesthetized by intramuscular (I.M.) injection with $35 \mathrm{mg} / \mathrm{kg}$ ketamin hydrochloride (Ketalar ampul, $50 \mathrm{~g} / \mathrm{ml}$, Eczacibasi Drug Company, Istanbul, Turkey) and $5 \mathrm{mg} / \mathrm{kg}$ xylasine hydrochloride (Rompun ampul, 23.32 mg/ml, Bayer, Istanbul,
Turkey). Anesthesia was maintained with additional doses of ketamin and xylasine. $24 \mathrm{G}$ canulas were inserted in to the right femoral artery and vein and monitored with a Siemens SC 6000 monitor (Danvers, MA, USA).

\section{Study Design}

The rabbits were randomly divided into four groups of seven animals. In Group I (control), $1 \mathrm{~mL}$ isotonic saline was given by intravenous infusion and $1 \mathrm{~mL}$ blood samples (to obtain basal vital measurements and biochemical parameters) were taken simultaneously at 0, 30, 60, 90, 120,180 , and 240 minutes. The rabbits in Groups II, III and IV (study groups) received $1 \mathrm{~mL}$ sterile saline at 30 minute intervals for 120 minutes, after which the sampling and injection frequency was increased to every 60 minutes. Sterile saline was given to Group I for the duration of the experiment, including at $\mathrm{t}_{0}$. Group II received $2 \mathrm{mg} / \mathrm{kg}$ endotoxin (Escherichia coli O55:B5, Sigma Chemical Company, USA) in sterile physiological saline (0.5 $\mathrm{mL} / \mathrm{kg}$ ) at $\mathrm{t}_{0}$. Sodium salt of ibuprofen (Sigma Chemical Company, USA) was dissolved in sterile saline at $77^{\circ} \mathrm{C}$ in a hot water bath. It was cooled down to $35-37^{\circ} \mathrm{C}$, then injected into Groups III and IV by slow infusion at a dose of $30 \mathrm{mg} / \mathrm{kg} / 5 \mathrm{~mL}$ at +30 and -30 minutes, respectively. Rabbits in the first group were followed for 240 minutes, and those in the remaining groups were followed until they died.

\section{Measurements}

Complete blood counts (CBC) were measured with an S+Coulter Counter (Fullerton, CA, USA). Blood samples for measuring Thromboxane $\mathrm{B}_{2}\left(\mathrm{TxB}_{2}\right)$ levels were collected in EDTA-tubes, centrifuged at $2000 \mathrm{rpm}$ for $20 \mathrm{~min}$ utes, and immediately stored at $-20^{\circ} \mathrm{C}$. Urine samples were collected for Prostaglandin $\mathrm{E}_{2}\left(\mathrm{PGE}_{2}\right)$ measurements by suprapubic aspiration, which completely emptied the bladder. The urine samples were immediately stored at $20^{\circ} \mathrm{C}$. $\mathrm{TxB}_{2}$ and $\mathrm{PGE}_{2}$ were determined by radioimmunoassay according to the manufacturer's protocol (Amersham Pharmacia Biotech Ltd, UK) using the Amerlex-M Magnetic Separation System at the Department of Biochemistry, College of Medicine, Istanbul University. Rectal temperatures were taken with a thermometer.

\section{Statistical Analysis}

All data are presented as mean \pm SEM. Parameters were compared over the study period using analysis of variance for repeated measures (SPSS version 10.01 for Windows). Where the F values were found to be significant, data were compared with Tukey's b test. Comparisons between the four groups at the same time point were analyzed by oneway analysis of variance followed by Tukey's-b post hoc test, where appropriate. $\mathrm{P}<0.05$ was considered statistically significant. 
Table I: Respiratory rate changes over time for each group

\begin{tabular}{|c|c|c|c|c|c|c|c|c|}
\hline \multirow[t]{2}{*}{ Time (min) } & \multicolumn{8}{|c|}{ Respiratory Rate (/min, mean \pm SEM) } \\
\hline & Group I & $\mathbf{N}$ & Group II & $\mathbf{N}$ & Group III & $\mathbf{N}$ & Group IV & $\mathbf{N}$ \\
\hline-30 & & & & & & & $64.6 \pm 5.3$ & 7 \\
\hline 0 & $39.6 \pm 3.1$ & 7 & $52.9 \pm 3.0$ & 7 & $68.7 \pm 5.3$ & 7 & $62.1 \pm 4.2$ & 7 \\
\hline 30 & $39.9 \pm 3.5$ & 7 & $96.1 \pm 8.7$ & 7 & $125.3 \pm 9.4$ & 7 & $68.0 \pm 6.4$ & 7 \\
\hline 60 & $42.1 \pm 4.8$ & 7 & $97.5 \pm 4.6$ & 6 & $73.4 \pm 5.4$ & 7 & $55.0 \pm 8.3$ & 7 \\
\hline 90 & $39.7 \pm 4.8$ & 7 & $95.3 \pm 6.4$ & 6 & $71.6 \pm 6.0$ & 7 & $68.0 \pm 11$ & 7 \\
\hline 120 & $38.6 \pm 4.2$ & 7 & $92.6 \pm 58.4$ & 5 & $72.9 \pm 6.9$ & 7 & $73.4 \pm 3.1$ & 7 \\
\hline 180 & $37.1 \pm 3.9$ & 7 & $56.4 \pm 50.6$ & 5 & $78.8 \pm 6.9$ & 7 & $70.4 \pm 8.0$ & 7 \\
\hline 240 & & 7 & $94.0 \pm 11.0$ & 3 & $79.6 \pm 6.0$ & 7 & $67.7 \pm 12.8$ & 7 \\
\hline 300 & & 7 & 115.0 & 1 & $67.0 \pm 12.8$ & 6 & $71.3 \pm 12.0$ & 7 \\
\hline 360 & & & 4.0 & 1 & $86.5 \pm 27.5$ & 2 & $53.3 \pm 19.9$ & 3 \\
\hline 420 & & & & & 112.0 & I & 84.0 & I \\
\hline 480 & & & & & 54.0 & 1 & 76.0 & 1 \\
\hline 540 & & & & & & & 100.0 & I \\
\hline 600 & & & & & & & 103.0 & I \\
\hline
\end{tabular}

$\mathrm{N}$ : number of rabbits that survived endotoxin administration

\section{Results}

Respiratory rate, heart rate, mean arterial blood pressure (MAP), body temperature, leukocyte and platelet counts, haematocrit levels, plasma $\mathrm{TxB}_{2}$ and urine PGE 2 levels in all groups are discussed below. None of the rabbits in Group I died after the experiment. The letter ' $N$ ' in Tables $1,2,3$ indicates the number of rabbits that survived endotoxin administration in the study groups.

\section{Respiratory rate}

This was significantly increased over 30, 60, 90 and 120 minutes in group II $(\mathrm{p}<0.001)$. In comparison, it was high at 30 minutes, but returned to $t_{0}$ levels after $60 \mathrm{~min}$ in group III rabbits.

The respiratory rate in Group IV was increased compared to the control group (Group I), but this difference was not statistically significant ( $p>0.05)$. This parameter in both Groups III and IV was lower than in Group II ( $<<0.001)$. There was no significant difference in respiratory rate between Groups III and IV ( $\mathrm{p}>0.05$, Table 1 and Fig. 1).

\section{Heart rate}

In Group II rabbits, which received endotoxin, heart rates significantly increased between 30 and 90 minutes, compared to $\mathrm{t}_{0}(\mathrm{p}<0.001)$.

Group III received endotoxin and ibuprofen at 0 and 30 minutes, respectively. In this group, heart rates were found to be increased at 30 and 60 minutes compared to $t_{0}(p>0.05)$. In this group, only one rabbit survived after 420 minutes.

Ibuprofen was administered to Group IV at $30 \mathrm{~min}$ and endotoxin at $\mathrm{t}_{0}$. An increase in heart rate was observed at 60 minutes, but this was not statistically significant ( $\mathrm{p}>$ $0.05)$.

When all groups were compared, heart rates at $60 \mathrm{~min}$ in both Groups II and III were significantly higher than in Group I ( $\mathrm{p}<0.05)$. Heart rates in Group IV were not significantly different from the control group ( $p>0.05$ ), but were significantly lower than both Groups II and III ( $\mathrm{p}<$ 0.01, Table 2 and Fig. 2).

\section{Mean arterial pressure}

MAP levels showed an obvious decrease at 30 minutes in group II, which received only endotoxin from $t_{0}$. MAP levels gradually decreased in group III, but showed a more regular gradual decrease in group IV.

When MAP levels between the groups were compared, it was observed that groups II and III had statistically significant decreases compared to groups I and IV ( $p<0.0001)$ at 30 minutes. Although MAP values decreased in group IV, there was an obvious difference between groups IV and I $(\mathrm{p}>0.05)$.

At 60 minutes, MAP levels started to decrease in group IV, and were statistically different from groups III and I ( $\mathrm{p}<$ $0.01)$. At 90 minutes, MAP levels in groups II and IV re- 


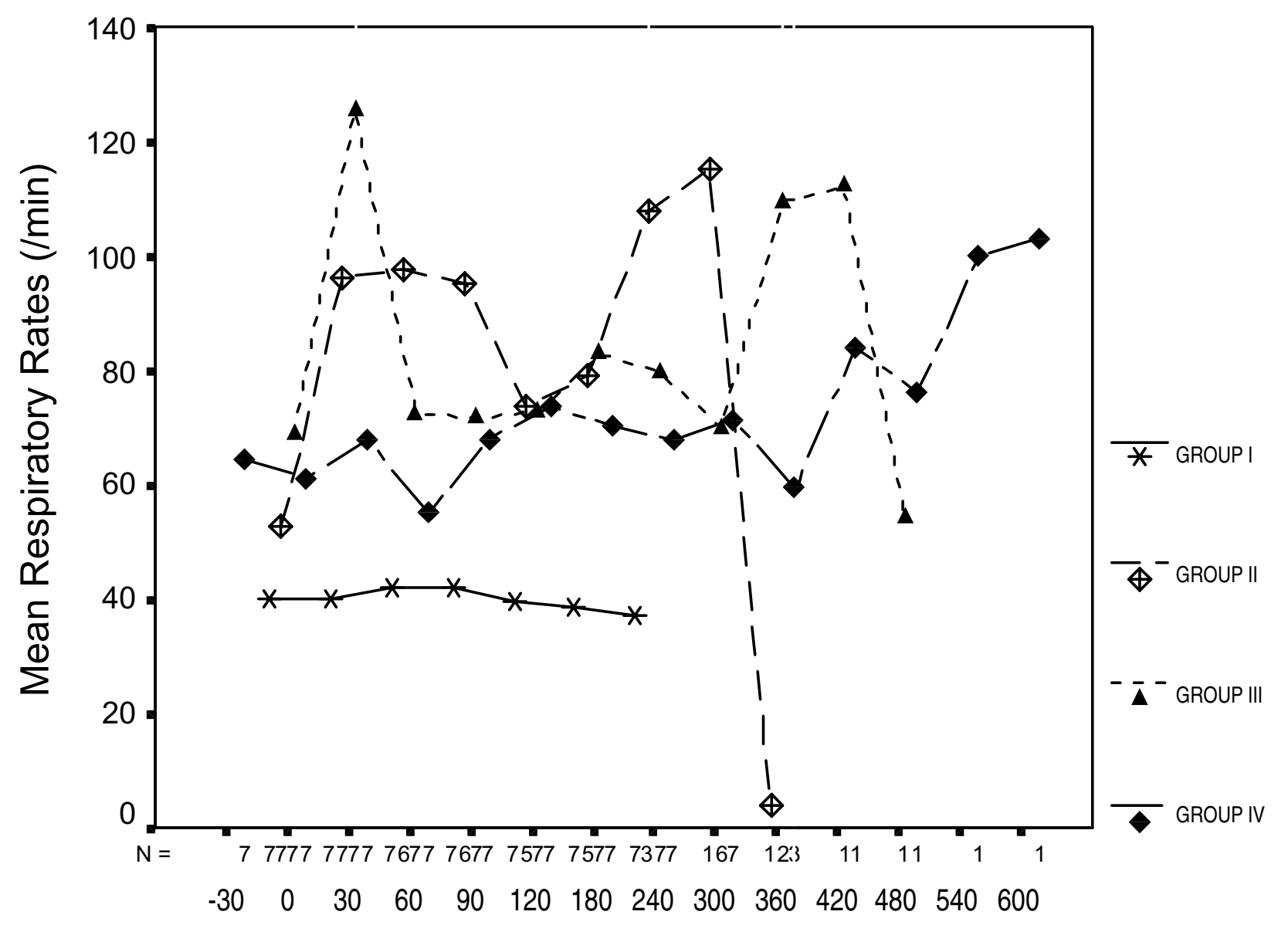

\section{Study Minutes}

Figure I

Mean respiratory rate values change over time for all groups. In both Groups III and IV, respiratory rates were lower than in Group II ( $p<0.00$ I). No significant difference was seen between Groups III and IV $(p>0.05)$.

mained statistically different from groups I and III $(\mathrm{p}<$ $0.01)$. At 120 minutes, they started to decrease in group III and statistically clear differences from group I ( $\mathrm{p}<0.05)$ could be seen. Arterial pressure in group III was found to be statistically higher than in both groups II and IV ( $\mathrm{p}<$ 0.02 ). At 180 and 240 minutes, MAP levels kept decreasing in groups II, III and IV. They were clearly lower in those three groups than in group I $(\mathrm{p}<0.001$, Table 3 and Fig. 3).

\section{Body temperature}

In general, there was no statistically significant difference in body temperature between the study groups, but there was a significant difference between Group I and the study groups ( $\mathrm{p}<0.001)$. In addition, hypothermia developed after endotoxin administration.

\section{White blood cell count}

There were fewer white blood cells in the study groups than in the control group, and the difference was statistically significant $(\mathrm{p}<0.0001)$. There was no significant difference in white blood cell counts between the endotoxinand ibuprofen-treated groups.

\section{Platelet count}

The number of platelets decreased after endotoxin administration, but ibuprofen had no effect on the platelet counts. 


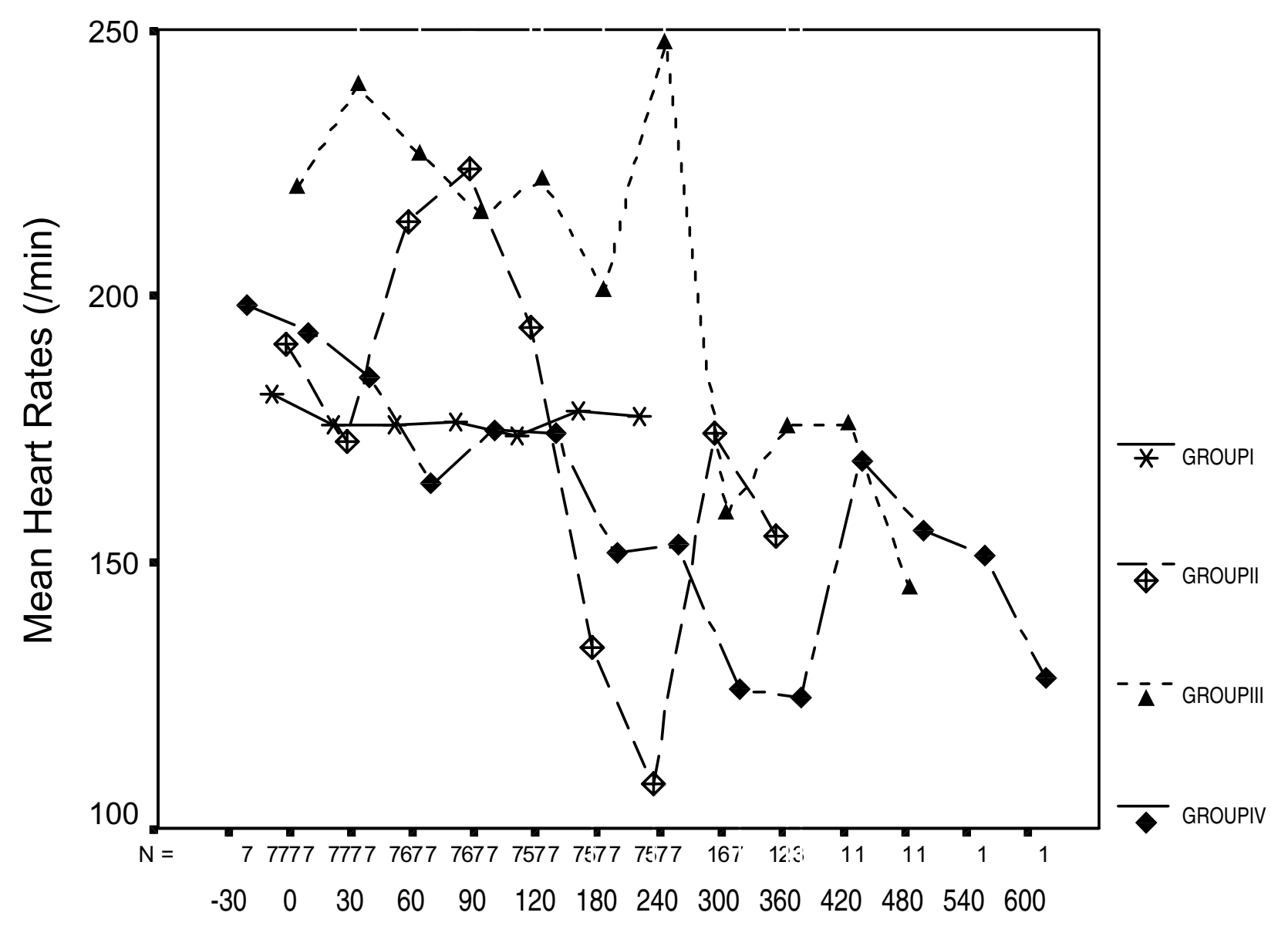

\section{Study Minutes}

\section{Figure 2}

Mean Heart rate values change over the time for all groups. In groups II and III, heart rates at 60 min were significantly higher than in Group I $(p<0.05)$. In Group IV they were not significantly different from controls $(p>0.05)$, but lower than II and III $(\mathrm{P}<0.0 \mathrm{I})$.

\section{Haematocrit levels}

These began to decrease gradually after $90 \mathrm{~min}$ in group II, and after $180 \mathrm{~min}$ in group III (when they were significantly lower than the onset levels). In group IV there were no statistically significant changes in haematocrit values throughout the study.

\section{Plasma $\mathrm{TXB}_{2}$ levels}

These increased following administration of endotoxin at $\mathrm{t}_{0}$ in Group II. Significant decreases in $\mathrm{TxB}_{2}$ levels were detected in Group III from 60 to 240 min, after injection of ibuprofen at $30 \mathrm{~min}$. Highly significant differences were observed between the $\mathrm{t}_{0}$ and 240 min samples ( $\mathrm{p}<$ $0.001)$.
In Group IV, plasma $\mathrm{TxB}_{2}$ levels were lowest between -30 minutes and $t_{0}$ (there was no significant difference between them). Plasma $\mathrm{TxB}_{2}$ levels began to increase after 30 minutes, which was significantly different from the -30 minute and $t_{0}$ values $(\mathrm{p}<0.005$ and $\mathrm{p}<0.01$, respectively).

When plasma $\mathrm{TxB}_{2}$ levels were compared between all groups, $t_{0}$ values were not significantly different between Groups II and III ( $p>0.05$ ), but they were significantly lower in Group IV than in any of the other groups ( $\mathrm{p}<$ $0.006)$. 


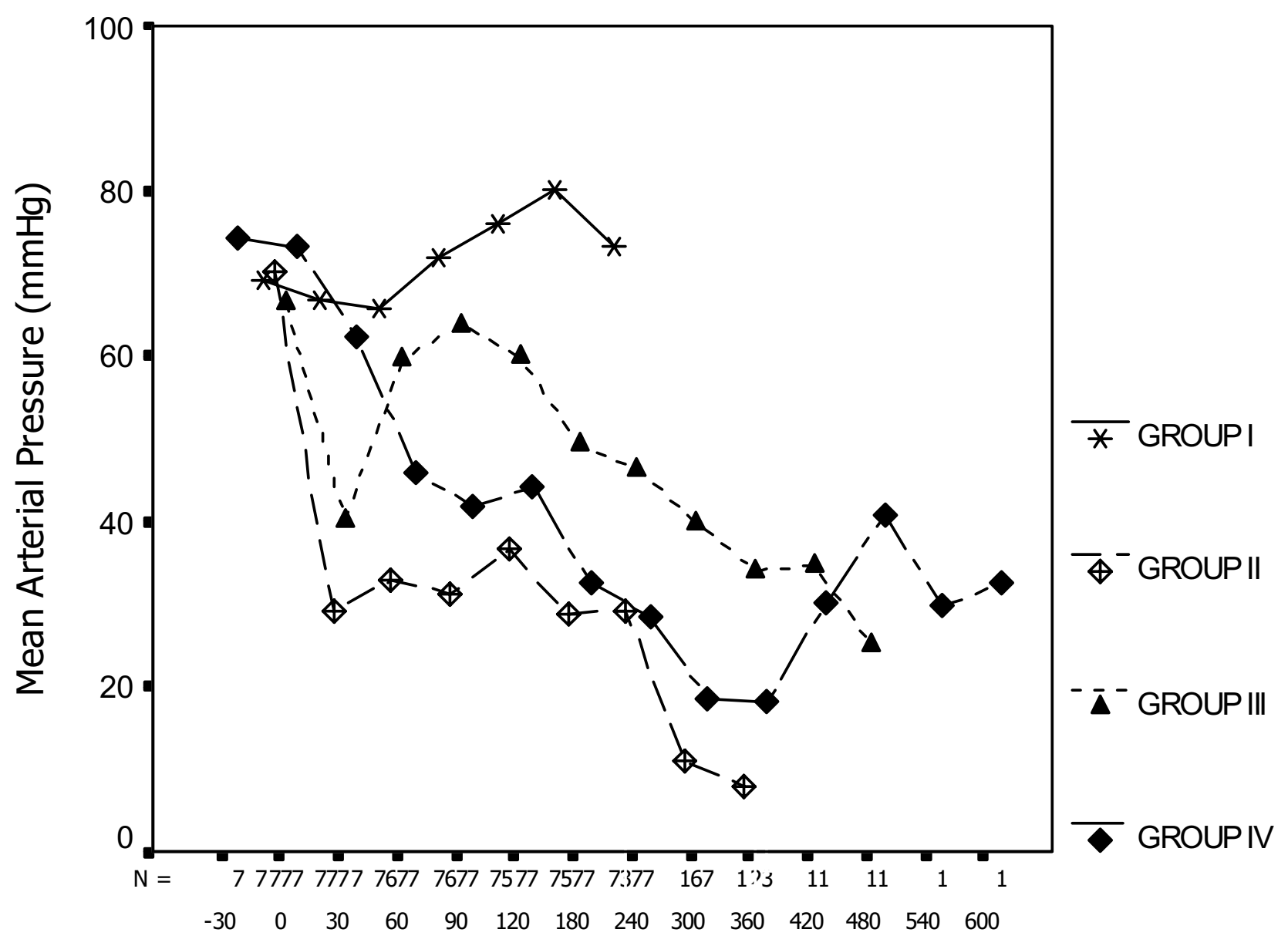

\section{Study Minutes}

Figure 3

Mean arterial blood pressure changes over time for each group. At 60 minutes, MAP levels started to decrease in group IV, and were statistically different from groups III and I $(\mathrm{P}<0.0 \mathrm{I})$. At 90 minutes, MAP levels in groups II and IV remained statistically different from groups I and III ( $<<0.0$ I). At I 20 minutes, they started to decrease in group III and statistically clear differences from group I $(p<0.05)$ could be seen. Arterial pressure in group III was found to be statistically higher than in both groups II and IV ( $<<0.02)$. At I 80 and 240 minutes, MAP levels kept decreasing in groups II, III and IV. They were clearly lower in those three groups than in group I $(p<0.00 I)$.

At 60 minutes, plasma $\mathrm{TxB}_{2}$ levels were reduced in both Groups II and III, but were increased in Group IV. They were significantly different between Groups II and III and the control group, but no significant differences were detected between study groups ( $\mathrm{p}>0.05$, Table 4 and Fig. 4 ).

\section{Urine $P_{G}$ levels}

These increased transiently after 30 minutes in Group II, and the increase at $60 \mathrm{~min}$ was significantly different from the 90 min sample. In Group III, urine PGE $_{2}$ levels were significantly increased at 30 min compared with $\mathrm{t}_{0}(\mathrm{p}<$ 0.001). However, they declined after 60 minutes. This de- cline continued to the 90 minute sample, so that $\mathrm{PGE}_{2}$ levels at both 60 and 90 min were significantly lower than the 30 minute value $(\mathrm{p}<0.001)$, but no different from $\mathrm{t}_{0}$ $(\mathrm{p}>0.05)$. In Group IV, $\mathrm{PGE}_{2}$ levels increased at $30 \mathrm{~min}$ compared to $t_{0}$, after administration of endotoxin. They then began to decrease from 60 and $120 \mathrm{~min}$, but the difference was only significant between 30 and $90 \min (\mathrm{p}<$ 0.025, Table 5 and Fig. 5).

\section{Survival rates}

Among the three endotoxic shock groups, the longest mean survival time was observed in Group IV (383.0 \pm 


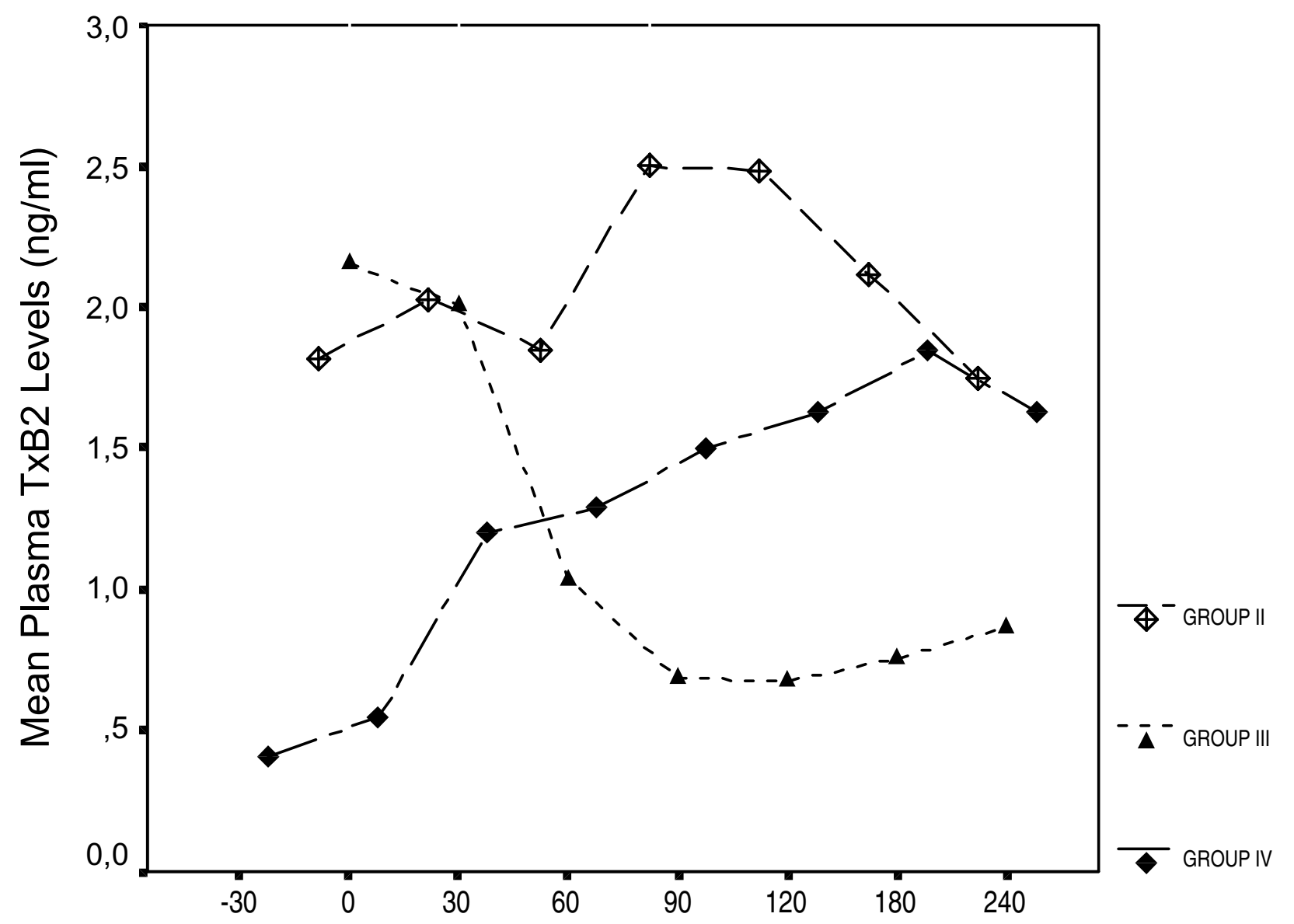

\section{Study Minutes}

\section{Figure 4}

Mean Plasma TxB2 values over time for all groups. Plasma $\mathrm{TxB}_{2} \mathrm{t}_{0}$ values were not significantly different between Groups II and III ( $p>0.05)$, but they were significantly lower in Group IV than in any of the other groups ( $<<0.006)$. At 60 minutes, plasma $\mathrm{TxB}_{2}$ levels were reduced in both Groups II and III, but were increased in Group IV. They were significantly different between Groups II and III and the control group, but no significant differences were detected between any of the study groups $(p>0.05)$

39.0 minutes). The survival rate in Group IV was significantly higher than in Group II (192.9 \pm 46.9 minutes), but not significantly higher than Group III (339.1 \pm 33.5 minutes) ( $p>0.05)$. In Group III, mean survival time was also significantly higher than in Group II $(\mathrm{p}<0.05)$. Mean survival times are shown in Fig. 6.

\section{Discussion}

Ibuprofen is a reversible, short-acting cyclooxygenase inhibitor, which particularly blocks the synthesis of thromboxane. Under in vitro conditions, it has been shown that ibuprofen stabilizes lyszomal membranes, restrains the secretion of lysozomal enzymes from granulocytes, and prevents the aggregation of platelets as well as the immigration of leukocytes [1-5].

NSAIDs were first used by Northover and Subramanian [11] in an endotoxic shock model in dogs, in order to improve hemodynamic disorders. In endotoxic or septic shock models, respiration pathway changes occur in the lungs. Metabolites of cyclooxygenase play an important role in this. Studies done with ARDS patients have shown that there is an increase in the number of PMNs in the lung and bronco-alveolar fluid, which cause an increase in elastase and other lysozomal enzymes [12]. Kopolovic et al.[13] have reported that respiration dysfunction and hy- 


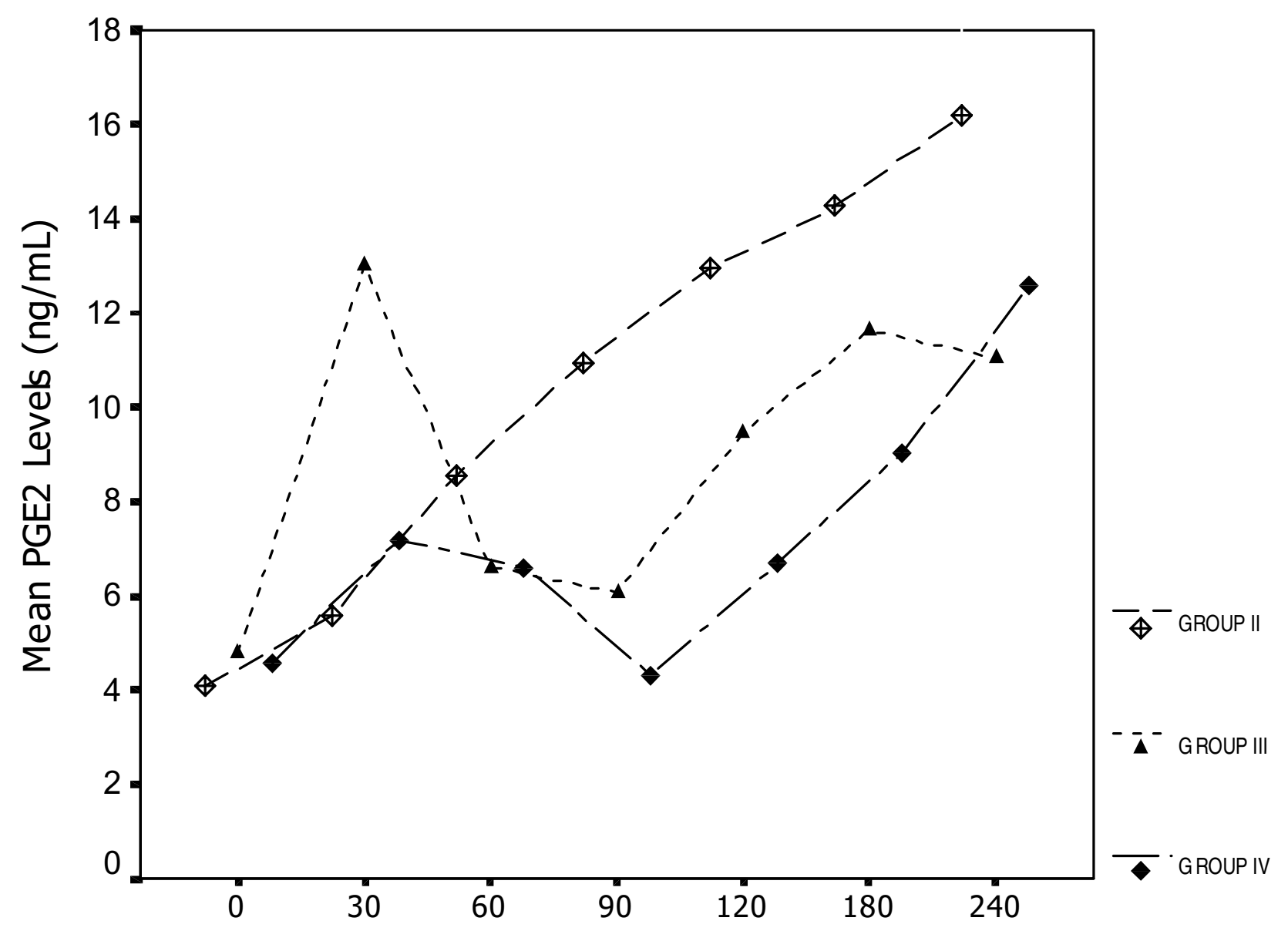

Study Minutes

Figure 5

Mean Urine $\mathbf{P G E}_{2}$ values over time for all groups. In Group III, urine PGE levels were significantly increased at 30 min compared with $t_{0}(p<0.00 I)$. They declined after 60 minutes and continued to decline at 90 minutes; levels at both 60 and 90 min were significantly lower than the 30 minute value $(p<0.00 \mathrm{I})$, but no different from $t_{0}(p>0.05)$. In Group IV, PGE 2 levels increased at $30 \mathrm{~min}$ compared to $\mathrm{t}_{0}$, then began to decrease from 60 and 120 min, but the difference was only significant between 30 and $90 \min (p<0.05)$.

poxemia were improved and pulmonary hypertension decreased in pigs that were administered ibuprofen after Pseudomonas aeruginosa infusion. In addition, the same researchers reported that treatment with ibuprofen caused a decrease in pulmonary shunt and lung edema. Balk et al. [14] used ibuprofen in a canine endotoxic shock model and found that it affected the extent of histological and morphometric lung injury.

In this study, the respiratory rates of the study groups were significantly higher than the control group at $30 \mathrm{~min}$. The respiration rates in both Groups III and IV were lower than in Group II right out to 360 minutes. Because the study groups (II, III, and IV) showed no remarkable differences after $360 \mathrm{~min}$, we presume that ibuprofen is not effective after this time. In addition, ibuprofen administration can prevent hyperpnoea if given before endotoxin.

Endotoxin administration may lead to hypotension and tachycardia [1]. In one study, Suffredini et al.[15] administered endotoxin to healthy volunteers and observed an increase in cardiac output of 53\%, a decrease in systemic vascular pressure of $46 \%$ and an increase in heart rate of 


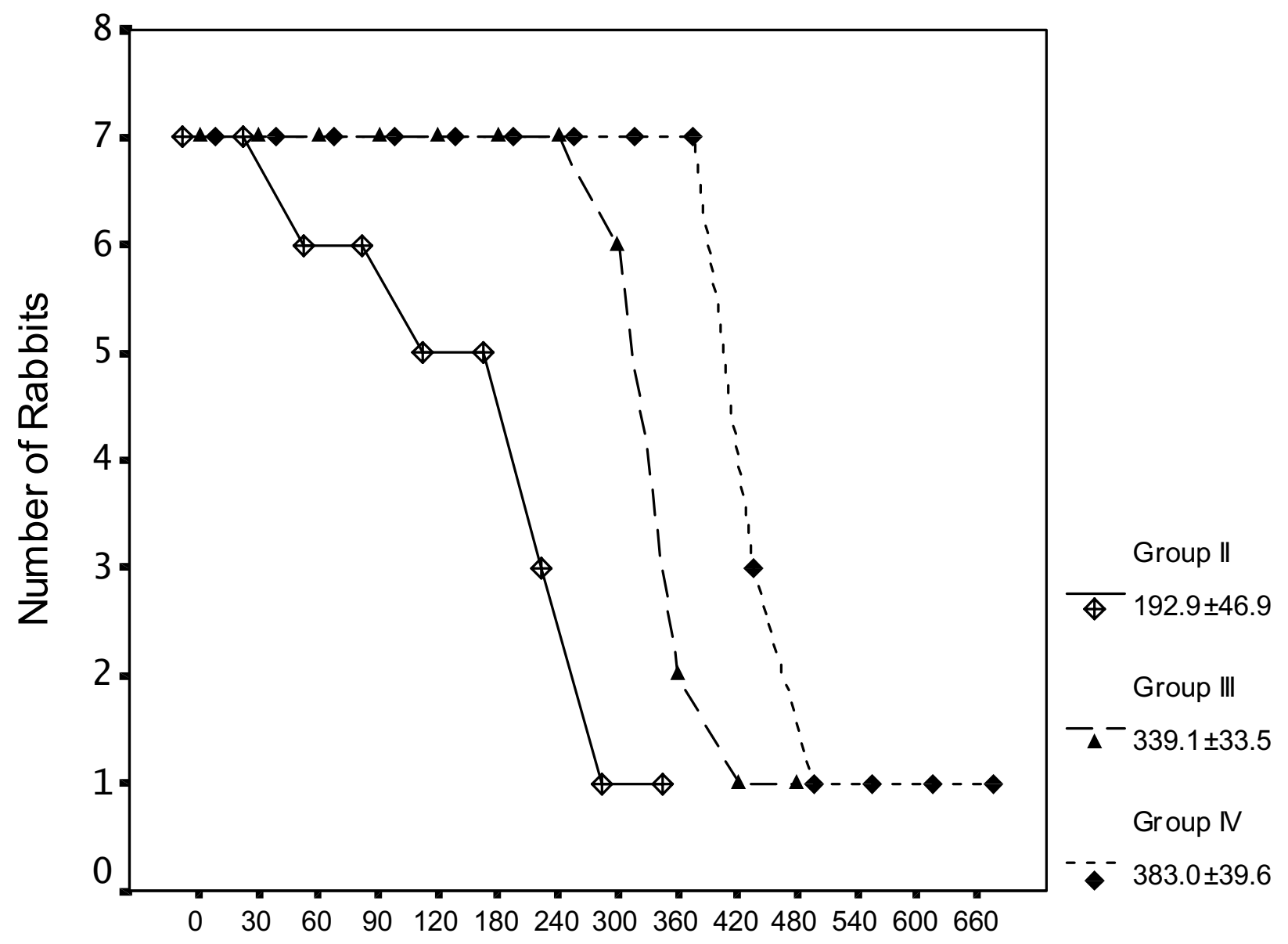

Study Minutes

\section{Figure 6}

Mean Survival times over time for all groups. In Group IV survival rate was significantly higher than in Group II, but not higher than Group III ( $p>0.05)$. In Group III, mean survival time was also higher than in Group II $(p<0.05)$.

$36 \%$. Previously, it has been observed that ibuprofen administration in endotoxic shock models prevents an increase in heart rate due to metabolic changes or regulation of oxygen dispersal at the tissue level $[16,17]$. In addition, another study by Revhaug et al.[18] reported that ibuprofen administration before endotoxin prevented an increase in heart rate. Yamanaka et al.[19] reported that there were no significant differences from the heart rates of controls in a similar study.

In our study, it was observed that pre-treatment with ibuprofen prevented heart rate increase. The effects of ibuprofen started at $90 \mathrm{~min}$ and lasted up to $180 \mathrm{~min}$ in the group that received ibuprofen after endotoxin. Thus, it appears that ibuprofen has no effect on secreted cyclooxyge- nase products, as it inhibits the cyclooxygenase enzyme. With this inhibition, new production of cyclooxygenase products is blocked. Therefore, the cyclooxygenase secreted by Group III caused tachycardia, but new formation of cyclooxygenase was inhibited by ibuprofen administration, so tachycardia was resolved. Therefore, it seems that ibuprofen administration has little effect on respiratory rate and heart rate.

Beck and Abel [20] reported that administration of ibuprofen before endotoxin blocked the sudden drop in mean arterial pressure in experimentally-induced endotoxic shock in dogs. Coran et al. [8] reported that mean arterial pressure was significantly higher in animals that received ibuprofen before induced shock than the control 
Table 2: Heart rate changes over time for each group

\begin{tabular}{|c|c|c|c|c|c|c|c|c|}
\hline \multirow[t]{2}{*}{ Time (min) } & \multicolumn{8}{|c|}{ Heart Rate (Imin, mean \pm SEM) } \\
\hline & Group I & $\mathbf{N}$ & Group II & $\mathbf{N}$ & Group III & $\mathbf{N}$ & Group IV & $\mathbf{N}$ \\
\hline-30 & & & & & & & $177.8 \pm 3.8$ & 7 \\
\hline 0 & $181.6 \pm 4.9$ & 7 & $172.7 \pm 4.4$ & 7 & $184.0 \pm 1.9$ & 7 & $168.1 \pm 4.3$ & 7 \\
\hline 30 & $175.7 \pm 4.3$ & 7 & $240.4 \pm 12.6$ & 7 & $239.6 \pm 9.4$ & 7 & $184.7 \pm 9.3$ & 7 \\
\hline 60 & $175.6 \pm 6.0$ & 7 & $227.2 \pm 8.6$ & 6 & $222.4 \pm 15.1$ & 7 & $164.8 \pm 11.3$ & 7 \\
\hline 90 & $176.1 \pm 5.2$ & 7 & $227.8 \pm 8.5$ & 6 & $184.6 \pm 4.9$ & 7 & $174.7 \pm 6.3$ & 7 \\
\hline 120 & $173.8 \pm 5.7$ & 7 & $190.0 \pm 30.2$ & 5 & $182.4 \pm 4.9$ & 7 & $174.1 \pm 5.1$ & 7 \\
\hline 180 & $178.1 \pm 5.3$ & 7 & $149.2 \pm 30.2$ & 5 & $200.6 \pm 24.5$ & 7 & $151.6 \pm 10.4$ & 7 \\
\hline 240 & $177.6 \pm 6.0$ & 7 & $84.3 \pm 49.6$ & 3 & $184.6 \pm 25.6$ & 7 & $153.1 \pm 19.2$ & 7 \\
\hline 300 & & 7 & 174.0 & I & $159.0 \pm 14.1$ & 6 & $126.1 \pm 17.0$ & 7 \\
\hline 360 & & & 155.0 & 1 & $175.5 \pm 24.5$ & 2 & $139.3 \pm 42.8$ & 3 \\
\hline 420 & & & & & 176.0 & 1 & 169.0 & 1 \\
\hline 480 & & & & & 145.0 & 1 & 156.0 & 1 \\
\hline 540 & & & & & & & 151.0 & 1 \\
\hline 600 & & & & & & & 128.0 & I \\
\hline
\end{tabular}

$\mathrm{N}$ : number of rabbits that survived endotoxin administration

Table 3: Mean arterial pressure changes over time for each group

\begin{tabular}{|c|c|c|c|c|c|c|c|c|}
\hline \multirow[t]{2}{*}{ Time (min) } & \multicolumn{8}{|c|}{ Mean Arterial Blood Pressure ( $\mathrm{mmHg}$, mean \pm SEM) } \\
\hline & Group I & $\mathbf{N}$ & Group II & $\mathbf{N}$ & Group III & $\mathbf{N}$ & Group IV & $\mathbf{N}$ \\
\hline-30 & & & & & & & $74.2 \pm 1.9$ & 7 \\
\hline 0 & $69.3 \pm 4.8$ & 7 & $70.1 \pm 3.1$ & 7 & $66.4 \pm 3.1$ & 7 & $73.3 \pm 3.5$ & 7 \\
\hline 30 & $66.9 \pm 4.5$ & 7 & $29.0 \pm 2.6$ & 7 & $40.1 \pm 6.9$ & 7 & $62.4 \pm 5.0$ & 7 \\
\hline 60 & $65.8 \pm 4.0$ & 7 & $32.9 \pm 1.1$ & 6 & $59.7 \pm 7.1$ & 7 & $45.9 \pm 16.8$ & 7 \\
\hline 90 & $71.9 \pm 6.0$ & 7 & $31.3 \pm 5.2$ & 6 & $63.8 \pm 6.5$ & 7 & $41.8 \pm 4.0$ & 7 \\
\hline 120 & $75.9 \pm 6.0$ & 7 & $36.5 \pm 7.2$ & 5 & $59.8 \pm 3.5$ & 7 & $44.3 \pm 4.1$ & 7 \\
\hline 180 & $79.9 \pm 4.7$ & 7 & $28.9 \pm 9.9$ & 5 & $49.2 \pm 5.4$ & 7 & $32.5 \pm 2.8$ & 7 \\
\hline 240 & $73.2 \pm 4.9$ & 7 & $29.2 \pm 14.4$ & 3 & $46.3 \pm 3.7$ & 7 & $28.5 \pm 1.4$ & 7 \\
\hline 300 & & 7 & 11.0 & 1 & $39.7 \pm 5.4$ & 6 & $16.9 \pm 1.5$ & 7 \\
\hline 360 & & & 8.0 & 1 & $34 . \pm 3.0$ & 2 & $24.6 \pm 3.9$ & 3 \\
\hline 420 & & & & & 34.7 & 1 & 40.7 & I \\
\hline 480 & & & & & 25.0 & 1 & 29.7 & I \\
\hline 540 & & & & & & & 32.4 & I \\
\hline 600 & & & & & & & 25.6 & I \\
\hline
\end{tabular}

$\mathrm{N}$ : number of rabbits that survived endotoxin administration

group in their experimental canine septic shock model. They indicated that MAP was consistently about $90 \%$ of the initial arterial pressure level. They also reported that when animals received ibuprofen after endotoxin; arterial pressure initially fell to about $50 \%$, then increased gradually and continued to be about $70 \%$ of initial levels.
In the present study, there was a general reduction in mean arterial blood pressure in group II, which received endotoxin. On the other hand, there was a sudden drop in MAP in Group IV, which received ibuprofen before endotoxin, whereas an increase in MAP was seen at 60 minutes in the group that received ibuprofen after endotoxin. 
Table 4: Plasma $\mathrm{TxB}_{2}$ values over time for each group

\begin{tabular}{|c|c|c|c|}
\hline \multirow[t]{2}{*}{ Time (min) } & \multicolumn{3}{|c|}{ Plasma TxB ${ }_{2}$ Levels (ng/mL, mean \pm SEM) } \\
\hline & Group II & Group III & Group IV \\
\hline-30 & & & $0.41 \pm 0.07$ \\
\hline 0 & $1.80 \pm 0.29$ & $2.15 \pm 0.34$ & $0.54 \pm 0.05$ \\
\hline 30 & $2.03 \pm 0.15$ & $2.00 \pm 0.36$ & $1.20 \pm 0.10$ \\
\hline 60 & $1.85 \pm 0.26$ & $1.00 \pm 0.35$ & $1.30 \pm 0.09$ \\
\hline 90 & $2.50 \pm 0.55$ & $0.69 \pm 0.09$ & $1.50 \pm 0.15$ \\
\hline 120 & $2.49 \pm 0.13$ & $0.67 \pm 0.08$ & $1.60 \pm 0.18$ \\
\hline 180 & $2.12 \pm 0.26$ & $0.76 \pm 0.08$ & $1.80 \pm 0.27$ \\
\hline 240 & $1.75 \pm 0.29$ & $0.87 \pm 0.13$ & $1.60 \pm 0.30$ \\
\hline
\end{tabular}

However, since initial MAP levels were not established in the study groups, it is possible that some other mediators were affecting blood pressure at the start of the experiment.

Ebong et al.[21] reported that all mice developed hypothermia in their model, where septic shock was induced by caecal ligation. While body temperature was above $34^{\circ} \mathrm{C}$ on day 1 , it later decreased below $34^{\circ} \mathrm{C}$. Haupt et al.[22] observed that fever in severe septic shock patients' was reduced after ibuprofen administration. However, they did not see a reduction in $\mathrm{PGE}_{2}$ levels, so they assumed that the reduction in fever was due to ibuprofen causing a decrease in IL-1 and TNF secretion, or due to the direct effect of ibuprofen on the central nervous system. The anti-pyretic effect of ibuprofen started at 4 hours, and lasted up to 24 hours after infusion.

The role of cytokines in hypothermia is not yet known, however, it is thought that the decrease in body temperature is dependent on a decrease in pyrojenic cytokines. During hypothermic sepsis, the response of cytokines and eicosanoids is higher than in febrile patients. Therefore, ibuprofen has been considered to be more useful in hypothermic patients than in septic shock patients [23]. In our study, changes in body temperature among study groups were not statistically significant.

The numbers of white blood cells are reduced in experimental animals induced with endotoxic shock [24]. Griffin et al. [4] reported that the number of white blood cells decreased after endotoxin administration in pigs. In addition, they found significant differences between endotoxin and endotoxin plus ibuprofen administration. In our study groups, the numbers of white blood cells were significantly lower than in the controls $(\mathrm{p}<0.0001)$. There were, however, no significant differences in the white blood cell counts between endotoxin and ibuprofen treated groups.

Haematocrit values appear to increase in some endotoxic shock models, but decrease in others $[10,19,20,22]$. It has been reported that ibuprofen has no effect on the consumption of systemic complement, thrombocytopenia, leucocytosis or leucopenia [25]. In our study, there was no increase in haematocrit levels. This may be related to the fact that 30-35 $\mathrm{mL}$ of blood was withdrawn from each rabbit. Ibuprofen also appeared to have no effect on haematocrit levels in our study.

The occurrence of isolated thrombocytopenia is higher than $50 \%$ in septic shock patients without disseminated intravascular coagulation [26]. The endotoxic shock experimentally induced by Griffin et al.[4] in pigs showed that the numbers of platelets decreased after endotoxin administration, but no significant differences were again seen between endotoxin and endotoxin plus ibuprofen ( $p$ $>0.05$ ). In our study, it was also observed that the number of platelets decreased after endotoxin administration, whilst ibuprofen had no effect. Many studies have shown that endotoxin administration can result in an acute decrease in the white blood cell count $[4,12]$, but we propose that ibuprofen has no effect on leukocyte and platelet counts.

It has been indicated that the pathway of cyclooxygenase products, such as $\mathrm{TxB}_{2}$ and $\mathrm{PGE}_{2}$, increases in many endotoxic shock models and plays an important role in a number of pathophysiological events [21,27].

$\mathrm{TxA}_{2}$ is a product of arachidonic acid and a potent platelet aggregator, whose levels increase during endotoxic shock. 
Table 5: Urine $\mathrm{PGE}_{2}$ values over time for each group

\begin{tabular}{lccc}
\hline Time (min) & \multicolumn{2}{c}{ Urine PGE $_{2}$ Levels $(\mathbf{n g} / \mathbf{m L}$, mean \pm SEM) } \\
\cline { 2 - 4 } & Group II & Group III & Group IV \\
\hline & & & \\
0 & & $4.8 \pm 0.3$ & $4.6 \pm 0.6$ \\
30 & $4.1 \pm 0.2$ & $13.0 \pm 0.3$ & $7.2 \pm 1.1$ \\
60 & $5.6 \pm 0.6$ & $6.6 \pm 0.9$ & $6.6 \pm 0.5$ \\
90 & $8.6 \pm 1.0$ & $6.0 \pm 0.3$ & $4.3 \pm 0.9$ \\
120 & $10.9 \pm 1.0$ & $9.5 \pm 1.3$ & $6.1 \pm 1.0$ \\
180 & $12.9 \pm 1.0$ & $11.6 \pm 0.8$ & $9.0 \pm 0.8$ \\
240 & $14.3 \pm 1.1$ & $11.0 \pm 1.0$ & $12.6 \pm 1.0$
\end{tabular}

Ibuprofen prevents the formation of $\mathrm{TxA}_{2}$, as well as platelet and leucocyte aggregation [12,21]. Fletcher et al.[28] reported that the levels of $\mathrm{TxB}_{2}$ were significantly reduced in rats by a combination of TNF and ibuprofen. Plasma $\mathrm{TxB}_{2}$ levels were also reduced by introducing ibuprofen into the faecal peritonitis rat model used by Wise et al.[29].

In this study, $\mathrm{TxB}_{2}$ levels decreased in the ibuprofen posttreated group compared with initial onset levels. In addition, it was found that the onset levels of $\mathrm{TxB}_{2}$ were significantly lower in the pre-treated group than the other groups. Making incisions into the rabbits may have caused an increase in pro-inflammatory cytokines. Low levels of $\mathrm{TxB}_{2}$ in group IV (at 0-30 min) were probably a result of ibuprofen inhibiting the increase which would normally be caused by these cytokines.

The endotoxic shock mouse model reported by Rosello et al.[30] showed that the levels of $\mathrm{PGE}_{2}$ were significantly lower in the ibuprofen-treated group than in controls. However, the levels of urine $\mathrm{PGE}_{2}$ were higher at 12 hours in both treated and untreated animals, but the difference was not statistically significant. In our study, it was observed that urine $\mathrm{PGE}_{2}$ gradually increased in group II after endotoxin administration. After treatment with ibuprofen, urine $\mathrm{PGE}_{2}$ levels decreased over the next 90 min, but later began to rise again. In another version of this study published previously, it was seen that ibuprofen reduced the endothelin production induced by endotoxin administration [31].

Griffin et al.[4] reported that there was no difference in mean survival times between control and ibuprofen preand post-treated groups. Arons et al.[23] performed a study with hypothermic septic patients, and reported that ibuprofen could be used to decrease mortality rates.
Schirmer et al. [32] found a transient 24-hour survival benefit in a rat model of septic shock. Fletcher et al[3] also reported that TNF-induced mortality could be reduced by using ibuprofen. Rosello et al. [30] found survival rates increased in mice treated with ibuprofen. In addition, Young and Passmore [33] reported that ibuprofen-treated canines with induced endotoxic shock had longer survival times than those treated with propylgallate. However, Bernard et al. [10] reported that there were no statistically significant differences between ibuprofen-treated and untreated animals with regards to their 30-day survival rate.

In our study, mean survival time was significantly longer in the ibuprofen-treated groups compared with the untreated group. In addition, the pre-treated group had a longer mean survival time than the post-treated group, but it was not statistically significant.

\section{Conclusions}

Ibuprofen appears to increase short-term survival due to its positive effect on various physiological parameters. Therefore, the use of ibuprofen at higher doses, over longer time periods, or in combination with other drugs in patients who are at risk of developing septic shock could be effective as a prophylaxis or treatment.

\section{Competing Interests}

This study was supported by Firat University Research Foundation.

\section{Acknowledgements}

It was presented as an oral session at ECMIDD I I, 0I-04 April 200 I, in Istanbul. This study was performed in the Department of Clinical Microbiology and Infectious Diseases, College of Medicine, Firat University, Elazig, and Department of Clinical Biochemistry, College of Medicine, Istanbul University, Istanbul, Turkey. 


\section{References}

I. Hubbard JD, Janssen HF: Increased microvascular permeability in canine endotoxic shock: protective effects of ibuprofen. Circ Shock 1988, 26(2): 169-83

2. Karima R, Matsumoto $\mathrm{S}$, Higashi $\mathrm{H}$ : The molecular pathogenesis of endotoxic shock and organ failure. Mol Med Today 1999, 5(3): $123-32$

3. Fletcher JR: The effects of ibuprofen on eicosanoid synthesis in sepsis. Crit Care Med 1999, 27(4):669-70

4. Griffin MP, Gore DC, Lobe TE, Flynn JF, Traber DL, Herndon DN: lbuprofen therapy in experimental porcine gram-negative septic shock. Resuscitation I991, 22(I):75-83

5. Jacobs ER, Soulsby ME, Bone RC, Wilson FJ, Hiller FC: Ibuprofen in canine endotoxic shock. J Clin Invest 1982, 70(3):536-4I

6. Fink MP, MacVittie TJ, Casey LC: Inhibition of prostaglandin synthesis restores normal hemodynamics in canine hyperdynamic sepsis. Ann Surg 1984, 200(5):619-26

7. Hulton NR, Johnson DJ, Willmore DW: Limited effects of prostaglandin inhibitors in Escherichia coli sepsis. Surg 1985, 98(2):291-7

8. Coran AG, Drongowski RA, Paik JJ, Remick DG: Ibuprofen intervention in canine septic shock: reduction of pathophysiology without decreased cytokines. J Surg Res 1992, 53(3):272-9

9. Herbertson M, Werner H, Studer W, Russell JA, Walley KR: Decreased left ventricular contractility during porcine endotoxemia is not prevented by ibuprofen. Crit Care Med 1996, 24(5):8I5-9

10. Bernard GR, Wheeler AP, Russell JA, et al: The effects of ibuprofen on the physiology and survival of patients with sepsis. The Ibuprofen in Sepsis Study Group. N Engl J Med 1997, 336(13):912-8

II. Northover BJ, Subramanian G: Analgesics-antipyretics drugs as antagonists of endotoxic shock in dogs. J Pathol Bacteriol 1962, 83:463-8

12. Rockwell WB, Ehrlich : Ibuprofen in acute-care therapy. Ann Surg I 990, 2 I I (I):78-83

13. Kopolovic R, Thrailkill KM, Martin DT, Ambrose T, Vento M, Carey LC, Cloutier CT: Effects of ibuprofen on a porcine model of acute respiratory failure. J Surg Res 1984, 36(4):300-5

14. Balk RA, Jacobs RF, Tryka F, Townsed JW, Walls RC, Bone RC: Effects of ibuprofen on neutrophil function and acute lung injury in canine endotoxic shock. Crit Care Med I988, I 6( I I): I I 21 -7

15. Suffredini AF, Fromm RE, Parker MM, Brenner M, Kovacs JA, Wesley RA, Parillo JE: The cardiovascular response of normal humans to the administration of endotoxin. $N$ Engl J Med 1989, 32 I (5):280-7

16. Bernard GR, Reines HD, Halushka PV, et al: Prostacyclin and thromboxane $A_{2}$ formation is increased in human sepsis syndrome. Effects of cyclooxygenase inhibition. Am Rev Respir Dis |99|, I44(5): |095-II0|

17. Martich GD, Parker MM, Cunnion RE, Suffredini AF: Effects of ibuprofen and pentoxiphylline on the cardiovascular response of normal humans to endotoxin. J Appl Physiol 1992, 73(3):9253l

18. Revhaug A, Michie HR, Manson JM, Watters JM, Dinarello CA, Wolf SM, Willmore DW: Inhibition of cyclo-oxygenase attenuates the metabolic response to the endotoxin in humans. Arch Surg 1988, I 23(2): 162-170

19. Yamanaka S, Iwao H, Yukimura T, Kim S, Miura K: Effect of the thrombocyte-activating factor antagonist, TCV-309, and the cyclo-oxygenase inhibitor, ibuprofen, on the hemodynamic changes in canine experimental endotoxic shock. $\mathrm{Br}$ J Pharmacol 1993, I I0(4): I50|-7

20. Beck RR, Abel FL: Effect of ibuprofen on the course of canine endotoxin shock. Circ Shock 1987, 23(I):59-70

21. Ebong S, Call D, Nemzek J, Bolgos G, Newcomb D, Remick D: Immunopathologic alterations in murine models of sepsis of increasing severity. Infection and Immunity 1999, 66 (I 2):6603-10

22. Haupt MT, Jastremski MS, Clemmer TP, Metz CA, Goris GB: Effect of ibuprofen in patients with severe sepsis: a randomized, double-blinded, multicenter study. The Ibuprofen Study Group. Crit Care Med I99I, I 9(I I): I339-47

23. Arons MM, Wheeler AP, Bernard GR, et al: Effects of ibuprofen on the physiology and survival of hypothermic sepsis. Ibuprofen in Sepsis Study Group. Crit Care Med 1999, 27(4):699-707
24. Mullen PG, Windsor AC, Walsh C], et al: Combined ibuprofen and monoclonal antibody to tumor necrosis factor-alpha attenuate hemodynamic dysfunction and sepsis-induced acute lung injury. J Trauma |993, 34(5):6 |2-2|

25. Bjornson AB, Knippenberg RW, Bjornson HS: Nonsteroidal antiinflammatory drugs correct the bactericidal defect of polymorphonuclear leukocytes in a guinea pig model of thermal injury. J Infect Dis 1988, I 57(5):959-67

26. Baumgartner JD, Calandra T: Treatment of sepsis: Update on causes and complications. J Crit Ilness 1999, 7:1233-54

27. Adams T, Traber DL: The effects of a prostaglandin synthetase inhibitor, ibuprofen, on the cardiopulmonary response to endotoxin in sheep. Circ Shock 1982, 9(5):48I-9

28. Fletcher JR, Collins JN, Graves ED, Luterman A, Williams MD, Izenberg SD: Tumor necrosis factor-induced mortality is reversed with cyclooxygenase inhibition. Ann Surg 1993, 2 I 7(6):668-75

29. Wise WC, Halushka PV, Knapp RG, Cook JA: Ibuprofen, methylprednisolone, and gentamicin as conjoint therapy in septic shock. Circ Shock 1985, I 7(1):59-7I

30. Rosello AM, Ferron-Orihuela JA, Ruiz-Cabello F, Garrote-Lara D, Fernandez-Mondeyar E, Delgado-Carrasco ML: Differential effects of IL-I $\beta$ and ibuprofen after endotoxic challenge in mice. $J$ Surg Research 1997, 67(2): 199-204

31. Vural P, Canbaz M, Akbulut A, Celik I: Effects of ibuprofen on plasma endothelin levels and some vital parameters during endotoxin shock in rabbits. Clin Chim Acta 2002, 3 I 6( I-2): I 01 -8

32. Schirmer WJ, Schirmer JM, Townsed MC, Fry DE: Effects of ibuprofen, indomethacin, and imidazole on survival in sepsis. Curr Surg 1987, 44(2): 102-5

33. Young JS, Passmore JC: Haemodynamic and renal advantages of dual cyclooxygenase and leukotriene blockade during canine endotoxic shock. Circ Shock 1990, 32(3):243-55

\section{Pre-publication history}

The pre-publication history for this paper can be accessed here:

http://www.biomedcentral.com/1471-2334/2/26/prepub 